\title{
Evaluation of Antibacterial Efficacy of Photodynamic Therapy vs. 2.5\% NaOCl against $E$. faecalis-infected Root Canals Using Real-time PCR Technique
}

\author{
Maryam Janani ${ }^{1}$, Farnaz Jafari ${ }^{2}$, Mohammad Samiei ${ }^{3}$, Farzaneh Lotfipour ${ }^{4}$, Ailar Nakhlband ${ }^{5}$, Negin

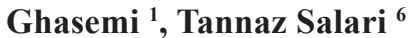 \\ ${ }^{1}$ Assistant Professor, Endodontics Department, Dentistry Faculty, Tabriz University of Medical Sciences \\ ${ }^{2}$ Department of Endodontics, Dental School, Tabriz Branch, Islamic Azad University \\ ${ }^{3}$ Associate Professor, Endodontics Department, Dentistry Faculty, Tabriz University of Medical Sciences \\ 4 Professor, Faculty of Pharmacy, Tabriz University of Medical Sciences, Tabriz, Iran \\ ${ }^{5}$ Research Center for Pharmaceutical nanotechnology, Tabriz University of Medical Sciences \\ ${ }^{6}$ Dentist, Tabriz University of Medical Sciences
}

Correspondence:

Department of Endodontics

Dental School, Tabriz Branch

Islamic Azad University

dr.jafarif@gmail.com

\begin{abstract}
Janani M, Jafari F, Samiei M, Lotfipour F, Nakhlband A, Ghasemi N, Salari T. Evaluation of Antibacterial Efficacy of Photodynamic Therapy vs. $2.5 \% \mathrm{NaOCl}$ against E. faecalis-infected Root Canals Using Real-time PCR Technique. J Clin Exp Dent. 2017;9(4):e539-44. http://www.medicinaoral.com/odo/volumenes/v9i4/jcedv9i4p539.pdf
\end{abstract}

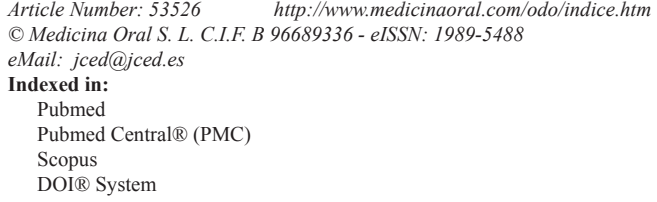

\begin{abstract}
Background: Bacteria like E. faecalis can produce intra- and extra-radicular biofilms. Theoretically, the adjustable penetration ability of lasers enables better access to root canal system. Therefore the aim of the present study was to compare the ability of photoactivated laser and $2.5 \% \mathrm{NaOCl}$ irrigation solution to eliminate $E$. faecalis from the root canals by real-time PCR technique.

Material and Methods: Sixty extracted human upper central incisors were selected and sterilized in an autoclave. The root canals were infected with E. faecalis (PTCC 1237, Persian Type Culture Collection, Iran) and then incubated for 24 hours. The samples were randomly divided into 3 groups. No intervention was made in the control group (group 1). In group 2, laser therapy was performed with a power of $100 \mathrm{~mW}$ by diode laser for 120 seconds. In group 3, the canals were irrigated with $5 \mathrm{~mL}$ of $2.5 \% \mathrm{NaOCl}$; then all the samples were sonicated in $15 \mathrm{~mL}$ of normal saline in test tubes in order to isolate the bacteria. DNA extraction was performed followed by real-time PCR technique for all the samples.

Results: Inhibition of bacterial growth in all the experimental samples was significantly more than that in the control group. There was a significant difference between photodynamic therapy and $2.5 \% \mathrm{NaOCl}$. The effect of $\mathrm{NaOCl}$ in all the samples was better than photodynamic therapy. The results of the mean $\mathrm{CT}$ (cyclic threshold) were $40,30.2$ and 15.35 for $2.5 \% \mathrm{NaOCl}$, photodynamic therapy and control group, respectively.

Conclusions: Based on the results of this experimental study, $2.5 \% \mathrm{NaOCl}$ eliminated E. faecalis from infected root canals more effectively compared to photodynamic therapy.
\end{abstract}

Key words: Photoactivated laser, Enterococcus faecalis, antibacterial agents, sodium hypochlorite. 


\section{Introduction}

A large number of microorganisms, including $E$. faecalis, have an important role in the etiology of periradicular lesions after root canal treatment $(1,2)$. E. faecalis has been isolated from $24-77 \%$ of periradicular lesions (2). This gram-positive facultative anaerobic microorganism is normally found in the oral cavity normal flora. It can penetrate into the dentinal tubules and cannot be completely eliminated during root canal preparation; therefore, it is one of etiologic factors for the failure of endodontic treatments $(3,4)$.

Laser beams can be used as an adjunct in endodontic treatment (5). It has been reported that dental lasers can improve access to areas of the tubular network that were previously inaccessible, an addition to the elimination of debris and removal of the smear layer (6). Therefore, they can decrease bacterial counts in the root canal (6). A new technique for the elimination of microorganisms from the root canal system is the use of low-level laser beams (7). In this technique, light-sensitive materials such as tolonium chloride are used. These materials bind to the cell membrane of bacteria, making them sensitive to laser beams. Due to the irradiation of laser beams, the molecules of the light-sensitive material move to higher energy levels and then transfer this excess energy to oxygen molecules to create free oxygen radicals. These free radicals destroy bacterial proteins, nucleic acid and lipids. This technique is referred to as photoactivated disinfection (PAD) (8). One of the advantages of this technique is an increase in heat $<0.5^{\circ} \mathrm{C}$, which is not significant clinically. PAD, in addition to the elimination of bacteria, accelerates bone formation processes in the periradicular area and is a strong stimulus for the healing of bone (7). This technique does not injure the host tissues and is very effective in eliminating $E$. faecalis from the root canal space (9).

Different techniques have been used for the evaluation of bacteria in the oral cavity and root canal system $(10,11)$, including bacterial culture and colony counting technique as one of the oldest techniques. However, the limitations of this technique include the uncultivable nature of some microorganisms, the high technique sensitivity during sampling and transfer to the laboratory, dependence on the technician's skill and expertise, etc (10). Molecular techniques have been introduced for identification of microorganisms with various advantages, including detection of cultivable and uncultivable species, high accuracy and specificity, high sensitivity, no need for controlling anaerobic conditions, the capacity to carry it out during antimicrobial therapy, easy transfer of the samples to the laboratory and detection of nonviable microorganisms, this last case is considered an advantage and a disadvantage. Therefore, this technique has become very popular (10). Various studies have used PCR-based techniques to evaluate endodontic and root canal microorganisms (12-14). Studies have shown that the accuracy of this new technique is several times that of culturing and colony counting technique (15).

Since no studies to date have used real-time PCR in this respect, this study was designed to compare the capacity of photoactivated laser technique in eliminating E. faecalis from the root canal system in comparison to irrigation with $2.5 \% \mathrm{NaOCl}$ solution.

\section{Material and Methods}

-Preparation of Samples

First, 60 maxillary central incisors with mature apices and straight roots, without any anatomic anomalies, were selected. The teeth had been extracted for periodontal reasons. The teeth were stored in 3\% chloramines $\mathrm{T}$ solution until used for the purpose of the study. The root surfaces were cleaned with ultrasonic devices, and cracked teeth and those exhibiting calcification on radiographic views were excluded from the study. The tooth crowns were removed at CEJ with a disk (D\&Z, Diamond, Germany) to leave a root length of approximately $12 \mathrm{~mm}$. Then the working length was determined $1 \mathrm{~mm}$ short of the apical foramen with the use of a \#20 K-Flexofile (Maillefer, Dentsply, Switzerland). Then the root canals were prepared with \#4 and \#3 Gates-Glidden drills (Maillefer, Dentsply, Switzerland) and \#40, 10\%, $\# 35,8 \%$ and $30,6 \%$ RaCe rotary files (FKG, Switzerland) using the crown-down technique in a uniform manner. Normal saline solution was used to irrigate the root canals. The smear layer was removed with $5.25 \%$ $\mathrm{NaOCl}$ (Taj Corp, Tehran, Iran) for 3 minutes, followed by $17 \%$ EDTA (Pulpdent Corp, MA, USA) for another 3 minutes. The teeth were sterilized in an autoclave at $121^{\circ} \mathrm{C}$ under 15 psi for 20 minutes. To confirm sterilization of the teeth, they were incubated in brain-heart infusion broth (Merck, Darmstadt, Germany) at $37^{\circ} \mathrm{C}$ for 24 hours. Then a pure bacterial culture of E. faecalis (PTCC 1237, Persian type culture collection, Iran) grampositive cocci was prepared. Before initiating the study, frozen bacteria $\left(-20^{\circ} \mathrm{C}\right)$ were defrosted and incubated on brain-heart infusion broth agar medium (Merck, Darmstadt, Germany) enriched with $7 \%$ sheep blood at $37^{\circ} \mathrm{C}$ under aerobic conditions. Some colonies were retrieved from the plates and transferred to bile esculin sodium azide agar (Merck, Darmstadt, Germany) and once again cultured at $37^{\circ} \mathrm{C}$ for 24 hours under aerobic conditions. The colonies growing on the surface of the agar medium were collected and adjusted to 0.5 standard McFarland concentration $(2.5 \times 108 \mathrm{CFU} / \mathrm{mL})$ in normal saline solution with the use of spectrophotometry. Then $200 \mathrm{~mL}$ of the bacterial solution were transferred into the root canal lumens with a micropipette. After 48 hours, all the root canals were dried with sterile paper points. Then the samples were randomly assigned to 3 groups $(n=20)$ : group 1 (control); group 2, photoactivated laser group; 
and group 3, 2.5\% $\mathrm{NaOCl}$ group. No intervention was carried out in the control group. In group 2, after placing $1.2 \mathrm{mg} / \mathrm{L}$ of tolonium chloride (PACT ${ }^{\circledR}$ Fluid Endo, Germany) for 3 seconds, the root canals underwent laser irradiation with the use of a flexible Denfotex endo-tip (Technologies Ltd), measuring $15 \mathrm{~mm}$ in length and 300 $\mu \mathrm{m}$ in diameter for 120 seconds. Diode laser (BWTEK Inc., Newark, DE), beams were used at a wavelength of $635 \mathrm{~nm}$ at an output power of $100 \mathrm{~mW}$ (16). The teeth in group 3 were irrigated with $5 \mathrm{~mL}$ of $2.5 \% \mathrm{NaOCl}$ (Taj Corp, Tehran, Iran).

All the teeth were transferred into $15-\mathrm{mL}$ test tubes containing normal saline solution and sonicated using a 34$\mathrm{kHz}$ and 180-W sonicator (Modstar Sonic 1835 Italy) for 6 minutes to separate the bacteria attached to the canal walls and suspend them in normal saline solution.

-Extraction of DNA

DNA was extracted from the prepared samples and then evaluated with real-time PCR. The tooth samples were stored in a freezer at $-20^{\circ} \mathrm{C}$ until the DNA was extracted. Under liquid nitrogen, $50 \mathrm{mg}$ from each sample was converted into powder and a lysing buffer containing 10\% SDS ( $\mathrm{NaCl}, 150 \mathrm{mM}$; Tris, $15 \mathrm{mM}$; EDTA, $10 \mathrm{mM} ; \mathrm{pH}=7.5$ ) was added and incubated overnight in proteinase $\mathrm{K}$ at $60^{\circ} \mathrm{C}$. After incorporation of 6-M NaO$\mathrm{Cl}$ and centrifugation, the supernatant was separated and rinsing was carried out with cold ethanol. Then ethanol was eliminated and the DNA was purified in $100 \mathrm{~mL}$ of TE buffer (Tris, $10 \mathrm{mM}$; EDTA, $1 \mathrm{mM}, \mathrm{pH}=7-8$ ) and stored at $-20^{\circ} \mathrm{C}$ in a freezer. The concentration and quality of DNA were determined by a biophotometer at 260 and $280 \mathrm{~nm}$ wavelengths.

-Electrophoresis with agarose gel

First, $1 \%$ agarose gel was prepared by dissolving $1 \mathrm{~g}$ of agarose powder in $100 \mathrm{~mL}$ of buffer (Tris-Borate-EDTA $0.5 \mathrm{X})$ and mixing with etidium bromide. Then the proliferation products of each gene were loaded in gel agar in the real-time PCR reaction and electrophoresis was carried out. This stage was carried out in order to confirm proliferation of the specific fragments of each gene and absence of non-specific products and pairing of the primers (dimer primer). In the present study, primers in which were prepared for previous studies were used.

-Enterococcus faecalis

The primers consisted of hflF:5-GCCAGATGGTTTACAAGCAC and hfIR:5-TATTCCGTTTCTTCG and the target gene was GroES/El Chaperone protein.

-Thermal cycles

The thermal cycles consisted of 32 cycles at $95^{\circ} \mathrm{C}$ for 25 seconds, $58^{\circ} \mathrm{C}$ for 40 seconds and $72^{\circ} \mathrm{C}$ for 90 seconds. To make sure of the absence of homology and complementation of the sequence of primers, their sequences in the BLAST website (NCBI) (www.ncbi.nlm.nih.gov/ blast) were compared with nucleotide sequences in the other sections of the genome.
-Real-time PCR

In the present study, real-time PCR unit, model BIORAD IQ5 (Australia), was used. The thermal timetable of the machine was carried out in 3 stages and activation of DNA in the first stage, which results in denaturing of the molecules of polymerase, took place at $95^{\circ} \mathrm{C}$ for $10 \mathrm{mi}-$ nutes; the second stage occurred at $95^{\circ} \mathrm{C}$ for 15 seconds and $55^{\circ} \mathrm{C}$ for 1 minute for 42 consecutive cycles, and the final stage or the melting cure to draw the dissociation curve after the final stage of the reaction was selected at $60-95^{\circ} \mathrm{C}$; the thermal changes were applied at a proper gradient. The reaction took place at a final volume of 25 $\mu \mathrm{L}$ in triplicate. The mixture of each reaction consisted of $5 \mu \mathrm{L}$ of SYBR-Green PRC Master Mix (ABI Company, Germany) and forward-and-reverse primers, each at a volume of $1 \mu \mathrm{L}$ with a concentration of $10 \mathrm{pM}$, genomic DNA (17) up to $20-100 \mathrm{ng} / \mu \mathrm{L}$ and distilled water were added to each to achieve a final volume of $25 \mu \mathrm{L}$. In the present study, a material with a green fluorescent dye was used, referred to as SYBR Green 1, Capable of being placed in a small groove of the two-stranded molecule to radiate a fluorescent light. The amount of the fluorescent light produced is directly related to the amount of the PRC product.

-Optimization of the Reaction

First, serial dilutions were prepared at 3, 6 and $9 \mathrm{pmol} /$ $\mu \mathrm{L}$ in order to determine the proper concentration and function of primers. In addition, 25 and $50 \mathrm{ng}$ of serial dilutions of DNA (control) were used in the real-time PCR tube for each gene in order to draw the standard curve. Based on the standard curve, the range of the optimal concentration of DNA pattern and the efficacy of the PCR was determined for the target gene. The reaction of serial dilutions for primers and standard DNA template took place for each gene in a dual manner in association with a non-template control (NTC) reaction. Changes in the target gene relative to the gene in question was evaluated and compared in the standard DNA of E. faecalis. Therefore, after completion of serial dilution reaction, from the standard DNA as a pattern, the standard curve was drawn for each gene based on the log of DNA concentration (the transverse axis) and the standard cycle or CT (the vertical axis). The standard curve gradient was used to calculate the efficiency of the proliferation reaction, which should be -3.0 to -3.7 : PCR efficacy percentage $=[10(-1 /$ slope $)-1 \times 100]$.

-Statistical Analysis

One-way ANOVA was used to compare the mean CT (cyclic threshold) between the three groups and if the test was significant, post hoc Tukey tests were used. Statistical significance was set at $P \leq 0.05$.

\section{Results}

The results of post hoc Tukey tests revealed statistically significant differences in the mean CT between the posi- 
tive control group and photodynamic and $2.5 \% \mathrm{NaOCl}$ groups, with higher means of CT in both photodynamic therapy and $2.5 \% \mathrm{NaOCl}$ groups compared to that in the positive control group $(P<0.001)$. In addition, the results of Tukey test showed a significant difference in mean CT between the photodynamic therapy and $2.5 \% \mathrm{NaOCl}$ groups, with higher mean $\mathrm{CT}$ in the $2.5 \% \mathrm{NaOCl}$ group compared to the photodynamic therapy group $(P<0.001)$. The means and standard deviations of $\mathrm{CT}$ in the positive control, photodynamic therapy and $25 \% \mathrm{NaOCl}$ groups were $15.33 \pm 0.99,30.20 \pm 2.29$ and $40 \pm 0.0$, respectively. In general, in the samples evaluated, the mean $\mathrm{CT}$ in $2.5 \% \mathrm{NaOCl}$ group was higher than that in the three groups, and the mean $\mathrm{CT}$ in the positive control group was less than that in the other groups.

One-way ANOVA was used to compare the means of $\mathrm{CT}$ between the three groups under study. The results showed significant differences between the three groups $(P<0.001)$. Post hoc Tukey tests were used to exactly determine the difference between each two group. Table 1 presents the results of Tukey tests. real-time PCR technique in root canals contaminated with E. faecalis. Based on the results, both the antibacterial agents used in this study resulted in significant decreases in E. faecalis counts compared to the control group. In this context, there was a significant difference between the laser photodynamic therapy and $\mathrm{NaOCl}$, with $2.5 \% \mathrm{NaOCl}$ exhibiting higher efficacy than photodynamic therapy.

In relation to the application of Er,Cr:YSGG laser as an antibacterial agent with in the root canals, Eldeniz et al. evaluated 40 root canals contaminated with $E$. faecalis in 4 groups of control, irrigation with $3 \% \mathrm{NaOCl}$ and two laser groups with $0.5-\mathrm{W}$ laser beams based on the size of the apical foramen. The results showed significantly higher decreases in bacterial counts compared to the control group. In addition, such a decrease in bacterial counts in the $3 \% \mathrm{NaOCl}$ group was more than that in the two laser groups (27).

In a study by Tennert et al. (28), the antibacterial effects of laser-activated $\mathrm{NaOCl}$ and laser alone on 72-hour-old E. faecalis biofilms, using the microbial culture techniques, were $92.7 \%$ and $99 \%$, respectively.

Table 1: The results of post hoc Tukey tests.

\begin{tabular}{|l|c|c|}
\hline Pair groups evaluated & Mean difference & $\boldsymbol{P}$-value* \\
\hline positive control and photodynamic therapy & -14.85 & $P<0.001$ \\
\hline positive control and $2.5 \% \mathrm{NaOCl}$ & -24.65 & $P<0.001$ \\
\hline photodynamic therapy and $2.5 \% \mathrm{NaOCl}$ & -9.8 & $P<0.001$ \\
\hline
\end{tabular}

*Tukey test.

\section{Discussion}

E. faecalis in one of the etiologic factors for the failure of endodontic treatments $(18,19)$. This microorganism can form intra- and extra-radicular biofilms, and it has been shown that these biofilms are very difficult to eliminate from the infected root canals (20). On the other hand, a large number of commonly used antibacterial agents might have no effect on the deep dentin layers (21). Different types of laser have so for been used in dentistry, especially in endodontics and the efficacy of many of them has been shown in eradication of $E$. faecalis $(22,23)$. The advantage of lasers in this context is that their penetration depth can be controlled and as a result they can gain access to areas with complex anatomic structure (24).

$\mathrm{NaOCl}$ solution in used as an intracanal irrigation solution due to its antibacterial properties and its reaction with the organic compounds of the dental pulp such as amino acids and fatty acid to dissolve them. Its low viscosity allows it to easily penetrate into the root canal. Another advantage of $\mathrm{NaOCl}$ is its availability and low cost (25). Sodim hypochlorite solution also has some disadvantages like poor taste and high toxicity (26).

In the present study, the antibacterial effects of laser photodynamic therapy and $2.5 \% \mathrm{NaOCl}$ were evaluated with
Rios et al. (29) carried out an electron microscopic study on the effect of PDT + toluidine blue on E. faecalis and showed that root canals treated with PDT for 30 seconds exhibited only $2.9 \%$ of residual bacteria; however, in the group treated with a combination of PDT and $6 \%$ $\mathrm{NaOCl}$, approximately $0.1 \%$ of bacteria remained after root canal therapy and this technique was considered an effective technique for decreasing microbial load of the root canal system, almost consistent with the results of the present study. However, in the present study, a lower concentration of $\mathrm{NaOCl}$ was used $\mathrm{n}$ order to decrease toxicity.

A study by Atieh (30) showed that real-time PCR was significantly more accurate in detecting P. gingivalis and A. actinomycetemcomitans compared to the culture technique. Zand et al. (11) carried out a study to determine colony forming units (CFUs) for the evaluation to the effect of photodynamic therapy and $\mathrm{NaOCl}$ on E. faecalis biofilms in different stages and concluded that photodynamic therapy and $2.5 \% \mathrm{NaOCl}$ were effective in completely eliminating E. faecalis biofilms. However, in the present study, $\mathrm{NaOCl}$ was more effective than photodynamic therapy in eliminating bacteria, which might be attributed to the high sensitivity of real-time PCR technique in detecting bacteria. The difference between the results of the present study and above mentioned re- 
search can be justified with the results of Sedgley et al. (15). Another justification for the inconsistency of results may be more efficacy of sodium hypochlorite than laser in complete denaturation of bacteria which make it impossible to detect them by PCR.

Sedgley et al. (15) compared the real-time qPCR and the culture technique, in which salivary samples were collected from 30 subjects. The real-time qPCR and the culture technique were able to detect $E$. faecalis in 5 samples (17\%) and 2 samples (7\%), respectively. They concluded that real-time qPCR is more accurate than the culture technique.

Karale et al. (3) evaluated the effects of $3 \% \mathrm{NaOCl}$, $2 \%$ CHX, HFAC (high-frequency alternating current) and normal saline (control) on E. faecalis. The results showed that $\mathrm{NaOCl}, \mathrm{CHX}$ and HFAC were effective in eliminating $E$. faecalis while $\mathrm{NaOCl}$ exhibited the highest antibacterial effect against $E$. faecalis, consistent with the results of the present study.

The results of studies by da Forta (31), Silva (32), Marinic (33) and Juric (34) in relation to the effect of photodynamic therapy compared to the positive control group on E. faecalis are consistent with the results of the present study; all the studies above have used microbial culture and colony count technique.

Like previous studies about antifungal activity of endodontic sealers (35), designing similar studies evaluating antifungal activity of laser against fungal infections of root canal system can be useful for future studies.

Since there are differences between different studies in relation to laser-activated materials, the techniques used for root canal cleaning and shaping, the type and power of the laser used, the concentration of $\mathrm{NaOCl}$, the technique used to determine colony counts, the molecular technique use to detect bacteria and the age of the biofilms used, it is not possible to directly compare the results of the present study with those of other studies, and such differences justify the discrepancies between the results of different studies. The advantage of the present study was the application of sensitive molecular techniques for the detection of bacteria.

The results of the present study showed a significant decrease in bacterial counts in the $2.5 \% \mathrm{NaOCl}$ group compared to the control group; in this context, almost no bacteria were detected in the $2.5 \% \mathrm{NaOCl}$ group by the PCR technique. The bacterial counts also decreased in the photodynamic therapy group but this decrease was less than that in the $2.5 \% \mathrm{NaOCl}$ group. The lower effect of photodynamic therapy on decreasing bacterial counts might be attributed to the fact that the existing laser probes can emit laser beam only through the tip of the probe; therefore, the beams have not reached all the straight surfaces of the root canal.

\section{Conclusions}

Based on the results of this in vitro study, in which real- time PCR technique was used, $2.5 \% \mathrm{NaOCl}$ solution resulted in a significant decrease in bacterial amounts of E. faecalis in contaminated root canals compared to the control group. In addition, $2.5 \% \mathrm{NaOCl}$ was more effective than photodynamic therapy in this respect.

\section{References}

1. Love R. Enterococcus faecalis-a mechanism for its role in endodontic failure. Int Endod J. 2001;34:399-405.

2. Stuart CH, Schwartz SA, Beeson TJ, Owatz CB. Enterococcus faecalis: its role in root canal treatment failure and current concepts in retreatment. J Endod. 2006;32:93-8.

3. Karale R, Thakore A, Shetty V. An evaluation of antibacterial efficacy of $3 \%$ sodium hypochlorite, high-frequency alternating current and $2 \%$ chlorhexidine on Enterococcus faecalis: An in vitro study. J Conserv Dent. 2011;14:2.

4. Denotti G, Piga R, Montaldo C, Erriu M, Pilia F, Piras A, et al. In vitro evaluation of Enterococcus faecalis adhesion on various endodontic medicaments. Open Dent J. 2009;3:120-4.

5. Stabholz A, Sahar-Helft S, Moshonov J. Lasers in endodontics. Dent Clin North Am. 2004;48:809-32.

6. Saydjari Y, Kuypers T, Gutknecht N. Laser Application in Dentistry: Irradiation Effects of Nd:YAG $1064 \mathrm{~nm}$ and Diode $810 \mathrm{~nm}$ and 980 $\mathrm{nm}$ in Infected Root Canals-A Literature Overview. Biomed Res Int. 2016;2016:8421656.

7. Lee MT, Bird PS, Walsh LJ. Photo-Activated Disinfection Of The Root Canal: A New Role For Lasers In Endodontics. Aust Endod J. 2004;30:93-8.

8. Holliday R, Alani A. Traditional and contemporary techniques for optimizing root canal irrigation. Dental update. 2014;41:51-2, 4,6-8 passim.

9. Fonseca MB, Júnior POT, Pallota RC, Filho HF, Denardin OVP, Rapoport A, et al. Photodynamic therapy for root canals infected with Enterococcus faecalis. Photomedicine and laser surgery. 2008;26:20913.

10. Sedgley C, Nagel A, Shelburne C, Clewell D, Appelbe O, Molander A. Quantitative real-time PCR detection of oral Enterococcus faecalis in humans. Arch Oral Biol. 2005;50:575-83.

11. Zand V, Milani AS, Amini M, Barhaghi MHS, Lotfi M, Rikhtegaran S, et al. Antimicrobial efficacy of photodynamic therapy and sodium hypochlorite on monoculture biofilms of Enterococcus faecalis at different stages of development. Photomedicine and laser surgery. 2014;32:245-51.

12. Dumani A, Yoldas O, Yilmaz S, Koksal F, Kayar B, Akcimen B, et al. Polymerase chain reaction of enterococcus faecalis and candida albicans in apical periodontitis from Turkish patients. J Clin Exp Dent. 2012;4:34-9.

13. Gupta-Wadhwa A, Wadhwa J, Duhan J. Comparative evaluation of antimicrobial efficacy of three herbal irrigants in reducing intracanal E. faecalis populations: An in vitro study. J Clin Exp Dent. 2016;8:e230-5.

14. Seelan RG, Kumar AA, Emil Sam RJ, Maheswari SU. Antimicrobial efficacy of different root canal sealers by using real-time polymerase chain reaction: An ex vivo study. J Conserv Dent. 2015;18:474-8.

15. Sedgley C, Nagel A, Dahlén G, Reit C, Molander A. Real-time quantitative polymerase chain reaction and culture analyses of Enterococcus faecalis in root canals. J Endod. 2006;32:173-7.

16. Bonsor S, Nichol R, Reid T, Pearson G. Microbiological evaluation of photo-activated disinfection in endodontics (an in vivo study). $\mathrm{Br}$ Dent J. 2004;197:337-41.

17. Klinke T, Klimm W, Gutknecht N. Antibacterial effects of Nd: YAG laser irradiation within root canal dentin. Clin Cardiol. 1996;19:232-8.

18. Jafari F, Samadi Kafil H, Jafari S, Aghazadeh M, Momeni T. Antibacterial Activity of MTA Fillapex and AH 26 Root Canal Sealers at Different Time Intervals. Iran Endod J. 2016;11:192-7.

19. Shahi S, Jeddi Khajeh S, Rahimi S, Yavari HR, Jafari F, Samiei M, et al. Effect of different mixing methods on the bacterial microleakage 
of calcium-enriched mixture cement. Minerva stomatol. 2016;65:269-

75.

20. Berutti E, Marini R, Angeretti A. Penetration ability of different irrigants into dentinal tubules. J Endod. 1997;23:725-7.

21. Noiri Y, Ehara A, Kawahara T, Takemura N, Ebisu S. Participation of bacterial biofilms in refractory and chronic periapical periodontitis. J Endod. 2002;28:679-83.

22. Bergmans L, Moisiadis P, Huybrechts B, Van Meerbeek B, Quirynen M, Lambrechts P. Effect of photo-activated disinfection on endodontic pathogens ex vivo. Int Endod J. 2008;41:227-39.

23. Soukos NS, Chen PS-Y, Morris JT, Ruggiero K, Abernethy AD, Som S, et al. Photodynamic therapy for endodontic disinfection. J Endod. 2006;32:979-84

24. Matsumoto K, Hossain M, Hossain MM, Kawano H, Kimura Y. Clinical assessment of Er,Cr:YSGG laser application for cavity preparation. J Clin Laser Med Surg. 2002;20:17-21.

25. Spencer H, Ike V, Brennan P. Review: the use of sodium hypochlorite in endodontics-potential complications and their management. $\mathrm{Br}$ Dent J. 2007;202:555-9.

26. Vinothkumar TS, Rubin MI, Balaji L, Kandaswamy D. In vitro evaluation of five different herbal extracts as an antimicrobial endodontic irrigant using real time quantitative polymerase chain reaction. J Conserv Dent. 2013;16:167-70.

27. Eldeniz A, Ozer F, Hadimli H, Erganis O. Bactericidal efficacy of Er, Cr: YSGG laser irradiation against Enterococcus faecalis compared with $\mathrm{NaOCl}$ irrigation: an ex vivo pilot study. Int Endod J. 2007;40:112-9.

28. Tennert C, Drews A, Walther V, Altenburger M, Karygianni L, Wrbas $\mathrm{K}$, et al. Ultrasonic activation and chemical modification of photosensitizers enhances the effects of photodynamic therapy against Enterococcus faecalis root-canal isolates. Photodiagnosis Photodyn Ther. 2015;12:244-51.

29. Rios A, He J, Glickman GN, Spears R, Schneiderman ED, Honeyman AL. Evaluation of photodynamic therapy using a light-emitting diode lamp against Enterococcus faecalis in extracted human teeth. J Endod. 2011;37:856-9.

30. Atieh MA. Accuracy of Real-Time Polymerase Chain Reaction Versus Anaerobic Culture in Detection of Aggregatibacter actinomycetemcomitan s and Porphyromonas gingivalis: A Meta-Analysis. J Periodontol. 2008;79:1620-9.

31. da Frota MF, Guerreiro-Tanomaru JM, Tanomaru-Filho M, Bagnato VS, Espir CG, Berbert FLCV. Photodynamic therapy in root canals contaminated with Enterococcus faecalis using curcumin as photosensitizer. Lasers Med Sci. 2015;30:1867-72.

32. Silva EJ, Coutinho-Filho WP, Andrade AO, Herrera DR, CoutinhoFilho TS, Krebs RL. Evaluation of photodynamic therapy using a diode laser and different photosensitizers against enterococcus faecalis. Acta Odontol Latinoam. 2014;27:63-5.

33. Marinic K, Manoil D, Filieri A, Wataha JC, Schrenzel J, Lange $\mathrm{N}$, et al. Repeated exposures to blue light-activated eosin $\mathrm{Y}$ enhance inactivation of $\mathrm{E}$. faecalis biofilms, in vitro. Photodiagnosis Photodyn Ther. 2015;12:393-400.

34. Jurič IB, Plečko V, Anić I, Pleško S, Jakovljević S, Rocca JP, et al. Antimicrobial efficacy of photodynamic therapy, Nd: YAG laser and QMiX solution against Enterococcus faecalis biofilm. Photodiagnosis Photodyn Ther. 2016;13:238-43.

35. Jafari F, Jafari S, Samadi Kafil H, Momeni T, Jamloo H. Antifungal Activity of Two Root Canal Sealers against Different Strains of Candida. Iran Endod J. 2017;12:98-102.

Acknowledgments

This article is financially supported by Dental and Periodontal Research Center, Tabriz University of Medical Sciences.

\section{Conflict of Interest}

The authors hereby report no conflicts of interest with regards to this work. 